\title{
Evaluating Reliability of Enterprise Architecture Based On Formal Fuzzy Models
}

\author{
S. Navaezadeh \\ Sama Technical and Vocational Training College, \\ Islamic Azad University, Mahshahr, Branch \\ Mahshahr, Iran
}

\author{
Rokhsareh Kabiri \\ Sama Technical and Vocational Training College, \\ Islamic Azad University, Mahshahr, Branch \\ Mahshahr, Iran
}

\begin{abstract}
The process of enterprise architecture (EA) is divided into strategic IT planning, EA development and EA implementation phases, respectively. Each phase is a prerequisite to the following phase. If the enterprise architecture planning (EAP) is not properly formulated during this process, its implementation would face problems and consequently a large amount of time and money would be wasted. EAP should be redefined to solve this issue. Definition of a method for the evaluation of EAP before the implementation of EA can be very useful in avoiding money and time loss caused by inappropriate EAP. A variety of methods are proposed around the world for evaluating EA but none of them can define and evaluate it in enterprises with uncertain processes or data. This research aims to present a new method for evaluating the reliability of EA while processes or data are uncertain. To achieve this goal, the products of fuzzy enterprise architecture (FEA) which demonstrate the behavior and sequence of processes and details of the enterprise are converted into fuzzy Petri nets. Afterwards, reliability evaluation is performed with fuzzy Petri nets which are executable models. In this method, uncertain processes and events can be easily modeled and evaluated. Therefore, the model proposed in this research is considered as a new method in EA. This method is executable and can be used in EA three-stage process.
\end{abstract}

Keywords: Enterprise Architecture Evaluation, Fuzzy Enterprise Architecture, C4ISR Framework, Fuzzy Colored Petri Nets

\section{INTRODUCTION}

The necessity of enterprise architecture can be observed in emerging large organizations, developing and designing complex information systems, emerging information systems for special purposes, the importance of organizations flexibility against external pressures like business changes, mission changes, enterprise structures and quick changes of technology. Organization architecture is a comprehensive method to describe future or current behavior and structure of organization processes, information systems and organization subunits. Therefore, organization architecture is presented and set on the basis of the main purpose of organization strategies. The main purpose of enterprise or organization architecture is to remove information technology as a tool, and to change it as organization resources along with other resources (financial, human, knowledge, experience and etc). They provide services for organization missions, and they should provide their own costs [3]. Before executing enterprise architecture, it's necessary to evaluate enterprise architecture so that the errors of modeling process are removed before final implementation. There are various frameworks for enterprise architecture modeling. In this paper, CaIsr 
International Journal of Computer Applications Technology and Research

Volume 5- Issue 1, 01 - 07, 2016, ISSN:- 2319-8656

framework is used. CaisR framework is abbreviation of the following names: command, control, computers, communications, intelligence, supervision and recognition. It is a comprehensive framework and it describes the architecture with some determined document and with the name of product. Nowadays, no framework has implemented samples like CaIsR [1]. In today's world, process and events are uncertain and indecisive. Therefore, using fuzzy concepts in enterprise architecture guarantees that the model is closer to the real world.

Recently, due to importance and application of fuzzy concept, they are used in most modeling branches so that modeled system is closer to the real world. In this paper, a model of organization architecture is used, and it describes uncertainly and in decisiveness a processes and data of enterprise architecture by using fuzzy concepts. With regard to the fact that Petri nets are simple and are strongly supported, these networks can be used to create on executable model of enterprise architecture. Then, by using executable model, the behavior and requirements of nonfunctional organization architecture can be evaluated. Operational event trace description (OV-6C) is used in enterprise architecture to describe the sequence and schedule of operation and to trace the activities of a scenario and critical sequences [4].this product is described by a fuzzy format. In this paper, this product is converted to colored petri networks, and then reliability of enterprise architecture is evaluated by using colored fuzzy Petri network. Up to now, some methods have been presented to evaluate reliability by using formal networks like queue network, Petr. network, process algebra, Atamata and etc. In this paper, since synchronization of various simultaneous activities is important when system reliability is evaluated, fuzzy Petri networks are used as a final model. In fact, fuzzy Petri networks present graphical displaying from the system along with its mathematic solution.

\section{PAPER ORGANIZATION}

In the second section of the paper, some definitions have been presented like CaISR framework, fuzzy colored Petri networks, fuzzy enterprise architecture and enterprise reliability. In the third section, enterprise architecture reliability is evaluated. In the fourth section, a case study is carried out to clarity the paper idea. Finally, the paper is concluded.

\subsection{CaIsR framework}

CaIsR framework is based on the process of performing the work. This framework involves three perspectives involving operational, systemic and technical perspectives [5].

Operational perspective refers to describing tasks and activities, components and operational nodes, necessities of information transmission between the nodes, and they are necessary for performing or supporting operations. Systematic perspective is a description of systems and the communication between then, and they are considered for performing or supporting a task. Technical architecture perspective refers to determining minimum set of rules for sequence, performance and dependencies between the components or dements of a system whose purpose is to guarantee the requirements specified for that system [4].

\subsection{Fuzzy colored Petri nets}

A normal Petri net is compatible with the classic logic. In practice, they are complex systems, and there is some uncertainty. Hence, such systems are modeled with Petri nets, these uncertainties must be displayed with ambiguous and inaccurate statements in Petri models, and this requires introducing fuzzy concept in Petri model. Therefore, in 1988, various kinds of Petri nets are designed by the research carried out by Looney and his colleagues in terms of Petri nets and artificial intelligence association, and it is compatible with Petri net theory [6]. Different tools support this network such as artifex and Design/CPN, CPN Tools 
International Journal of Computer Applications Technology and Research

Volume 5- Issue 1, 01 - 07, 2016, ISSN:- 2319-8656

software. The software of CPN tools is presented by Aarhus university of Denmark. The first version of this software was presented in the market in 2001. The language used for developing and correcting data is standard ML [2]. By using graphic user interface of this software, models of colored Petri nets, can be designed. Also, by using this animating software (step-by-step execution) in models of colored Petri nets as well as creating a space of colored Petri nets model, question definitions of model behavior and creating output files to displaying simulation results of models can be presented.

\subsection{Fuzzy enterprise architecture}

Fuzzy enterprise architecture (FEA) is a complete and comprehensive model describing and displaying enterprise architecture products by considering uncertainly in process and data of enterprise architecture. The model of fuzzy enterprise architecture (FEA) shows architecture products in the form of new frames and formats. In this way, the process of enterprise architecture designing can be obtained. Through using this model, enterprise architecture can be evaluated by Fuzzy colored Petri nets [7]. Also, the model of fuzzy enterprise architecture involves capability of enterprise architecture structure and describing behavioral concepts.

\subsection{The reliability of enterprise architecture}

In enterprise architecture level, reliability is used to displaying reliability degrees of appropriate functions in all enterprise processes or appropriate functions and applications of a set of components in specified time period. It is important to mention that if a component fails (or it does not function appropriately), then they does not mean that while enterprise architecture is unreliable. Each component, in fact, indicates a part of an organization where it provides services. These components (services) meet final targets of the organization when they cooperate with each other.

In order to evaluate the reliability of an organization, reliability evaluation of each component is proposed. Evaluation of reliability in whole enterprise is the result of evaluating reliability of each component and the way of interacting and communicating with each other during execution of a process. In this research, the purpose is to evaluate reliability in a process of enterprise architecture.

\section{EVALUATION OF ENTERPRISE ARCHITECTURE RELIABILITY}

In this paper, accurate computation of whole enterprise architecture reliability is disregarded, and the way of computing reliability in a process is explained. In order to reach this purpose, (ov-6c) product that shows the procedures of interacting different components when a process is executed is firstly converted to fuzzy colored Petri net. Finally, in order to compute reliability of each process, a success degree of $\mathrm{f}$ is defined for each transmission in fuzzy Petri net. Success degree specifies the ability of activating transmission. If it occurs erroneously component output is not corrects, this event will not occur. In other words, error in 1-f,and it means missing data.

It is supposed that taken in transmission entry of it carries a value, and this shows the success degree to that place; that is process execution is successful in $\mathrm{D}$ degree. when transmission is activated, values showing success degree of (D) are changed to $\mathrm{D} * \mathrm{f}$, and token obtains a new activation and fire probability. $\mathrm{D} * \mathrm{f}$ is used instead $\mathrm{f} f$, and this concept is shown in figure (1) [8]. In the first step of the process (Petri net), the success degree equals one. 


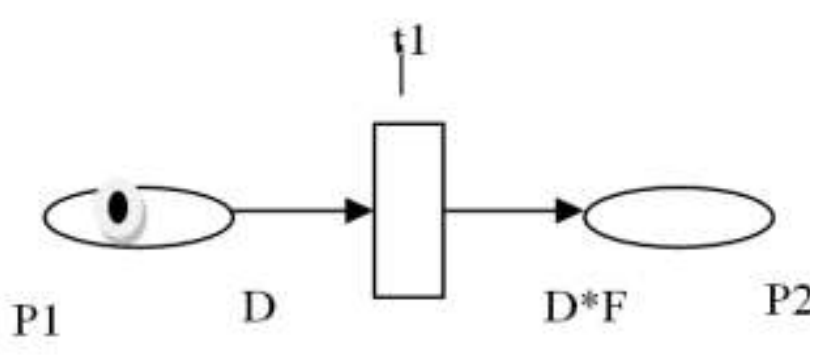

D: the location of maintaining success rate= reliability

Figure (1) : Reliability by using fuzzy Petri net

It means that if, during process execution, reliability is equal to $\mathrm{D}$ in $\mathrm{P} 1$ component, it changes to $\mathrm{D} * \mathrm{f}$ when passes $\mathrm{t} 1$. This procedure is repeated until while process is executed. With regard to this fact that the process passes through some components, reliability will be different.

\section{CASE STUDY AND EVALUATION OF PROPOSED METHOD.}

In order to classify discussion and proposed idea, a system is designed and tested. It's likely that generalization of this method requires using it in many real systems so that probable defects are removed. In this research, the amount of reliability and error is considered the same in all components. Hence, differences of processes reliability are the results of the number of procedures. In other words, a process passing through more components, its reliability will considerably decrease.

\section{1. explaining assumed system of hotel reservation}

A record system of centralized request is a computerized program used for recording rents and managing payments in a hotel. Here, a hotel reservation system based on web is selected. Organizations or other services transfer their own request to this service when hotel reservation is needed.
According to various conclusions of system, it announces possibility of reservation. Such systems must have higher error tolerance [8]. The product of describing event/operational tracing (OV-6C) and event/systemic tracing (SU-loc) in hotel reservation hotel has been shown in figure (2). In this product, since the hotel response to applicant enterprise is fuzzy, fuzzy product (OV-6C) is considered.

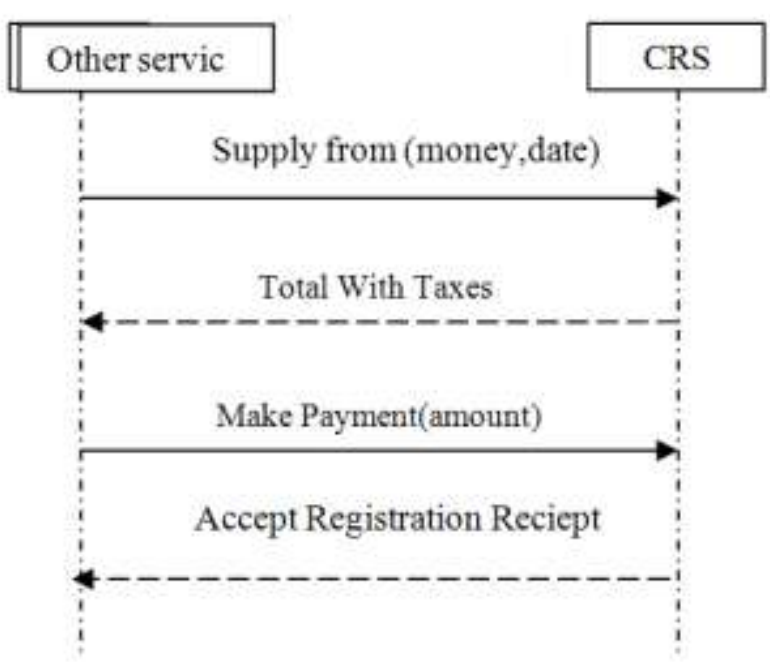

Figure (2): The product of describing event/operational tracing (OV-6C) and event/systemic tracing (SV-10C) for hotel reservation system [8].

In order to present fuzzy Petri nets in hotel representation hotel, conditions, events and rules must be specified in the first step.

Step1: 
International Journal of Computer Applications Technology and Research

Volume 5- Issue 1, 01 - 07, 2016, ISSN:- 2319-8656

Events

table (1): Rules

1. Money

$\checkmark$ Almost enough, Money $>500$

$\checkmark \quad$ Middle $200<$ Money<500

$\checkmark \quad$ Not enough Money<200

2. Date

$\checkmark \quad$ Valid (reservation date for more than 10 days)

$\checkmark \quad$ Invalid (reservation date for less than 10 days)

3. Output

$\checkmark \quad$ Almost acceptable (acceptance is performed)

$\checkmark$ Acceptable (acceptance is performed somewhat. If a person requests a room fpr five days, it is reserved for three days).

$\checkmark \quad$ Not acceptable (acceptance is not performed)

\begin{tabular}{|c|c|c|c|}
\hline Rule & Event & Condition & State \\
\hline R1 & $\begin{array}{r}\text { P12 :money is not } \\
\text { enough } \\
\text { P15: Date is invalid }\end{array}$ & P12 AND p15 & P18: Not acceptable \\
\hline R2 & $\begin{array}{l}\text { P12: Money is not } \\
\text { enough } \\
\text { P14: Date is valid }\end{array}$ & P12 AND P14 & P18: Not acceptable \\
\hline R3 & $\begin{array}{l}\text { P11: Money is enough } \\
\text { P15: Date is invalid }\end{array}$ & P11 AND P15 & P17: Acceptable \\
\hline $\mathrm{R} 4$ & $\begin{array}{l}\text { P11: Money is enough } \\
\text { P14: Date is valid }\end{array}$ & P11 AND P14 & P16: Almost acceptable \\
\hline R5 & $\begin{array}{l}\text { P13: Money is middle } \\
\text { P15: Date is invalid }\end{array}$ & P13 AND P15 & P17: Acceptable \\
\hline R6 & $\begin{array}{l}\text { P13: Money is middle } \\
\text { P14: Date is valid }\end{array}$ & P13 AND P14 & P17: Acceptable \\
\hline
\end{tabular}


International Journal of Computer Applications Technology and Research

Volume 5- Issue 1, 01 - 07, 2016, ISSN:- 2319-8656

Finally, the final result of fuzzy Petri net in hotel reservation system is shown in figure (3).

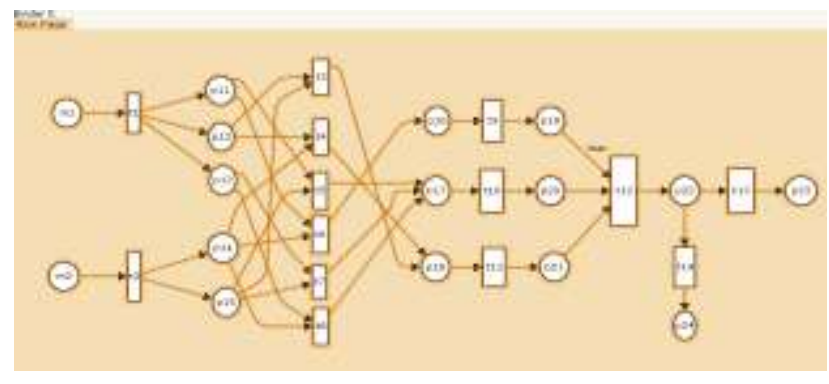

Figure3: Colored fuzzy Petri net of hotel reservation system

As it is observed in figure 3, if reliability is higher in P22, it is transferred to P23; Otherwise, it is transferred to P24, and it comes to end.

\subsection{Numerical evaluation of supposed system}

After preparing fuzzy Petri net, reliability is evaluated in the network.

Example 1: it is supposed that money $=400$ (average value of money) and $20^{\text {th }}$ day of future month (that is, day is valid because it involves more than 10 days. with regard to these inputs, the route is as follows:

$\mathrm{t} 1, \mathrm{t} 2 \rightarrow \mathrm{t} 8 \rightarrow \mathrm{t} 10 \rightarrow \mathrm{t} 12 \rightarrow \mathrm{t} 13$ or $\mathrm{tx}$

It is supposed that all transmissions are fired with probability of 0.94 (that is, reliability of each component is 0.94 ), except $\mathrm{t} 1$ and $\mathrm{t} 2$ whose probable transmissions are equal to one.

The method of computing reliability

$\mathrm{t} 1, \mathrm{t} 2=1$

$\mathrm{t} 3, \mathrm{t} 4, \mathrm{t} 5, \mathrm{t} 7, \mathrm{t} 8=0.94$

$\mathrm{t} 10=0.94 * 0.94=0.88$

$\mathrm{t} 12=0.94 * 0.88=0.82$ $\mathrm{t} 13, \mathrm{t} 14=0.94 * 0.82=0.77$

Final reliability is 0.77 , and this is very low because capability of each transmission is considered as 0.94 . Therefore, two methods are proposed to create reliability of whole enterprise architecture:

1) Increasing reliability of each component (service)

2) By signing, the number of procedures or transmissions (components decreases in while enterprise architecture because reliability decreases in passing through each transmission (component) in enterprise architecture. In other words, the process having more procedures has lower reliability since in the process passing through each component, the reliability is multiplied by success rate of that component. As it is clear, success rate or reliability of a component is never $100 \%$ (one).

\section{CONCLUSION}

Various methods have been proposed to evaluate enterprise architecture, but none of them can describe and evaluate enterprise architecture when the enterprise has indecisive data or processes. In this research, enterprise architecture is evaluated for the first time by considering indecisive and fuzzy conditions. Also, fuzzy formal methods having strong mathematical support are used in this research for evaluation, and this indicated accuracy and reliability of the proposed method. This method is executable, and it has great value and importance because, by applying it on several real systems, its probable defects can be removed, and it can be used by enterprise architects.

The method proposed in this research is used to evaluate reliability of a component in enterprise architecture. Through developing this method in all components of enterprise architecture and combining and aggregating all of them, a complete and comprehensive method can be obtained for whole enterprise architecture, and this purpose can be achieved in future researches. Since this model uses formal models such as Petri net, it is accurate, and it can be 
International Journal of Computer Applications Technology and Research

Volume 5- Issue 1, 01 - 07, 2016, ISSN:- 2319-8656

used by enterprise architects. Defects of this model can be completely removed by accurate investigation of this model and by using it in supposed enterprise architecture.

In addition, in order to evaluate other enterprise architecture metrics, a similar method (using fuzzy Petri net) can be used, and it will be discussed in future researches. The results of comparing the proposed model with other models of enterprise architecture evaluation

\begin{tabular}{|l|l|l|l|l|}
\hline $\begin{array}{l}\text { Evaluation } \\
\text { criterion }\end{array}$ & $\begin{array}{l}\text { Architecture } \\
\text { model }\end{array}$ & $\begin{array}{l}\text { Levis } \\
\text { model }\end{array}$ & $\begin{array}{l}\text { OSAN } \\
\text { model }\end{array}$ & $\begin{array}{l}\text { The } \\
\text { proposed } \\
\text { mode }\end{array}$ \\
\hline $\begin{array}{l}\text { application } \\
\text { and } \\
\text { function }\end{array}$ & No & Yes & Yes & Yes \\
\hline $\begin{array}{l}\text { supporting } \\
\text { object }\end{array}$ & No & Yes & Yes & Yes \\
\hline $\begin{array}{l}\text { Evaluating } \\
\text { qualitative } \\
\text { feature }\end{array}$ & efficiency & efficiency & efficiency & efficiency \\
\hline $\begin{array}{l}\text { Obtaining } \\
\text { the rates } \\
\text { involving } \\
\text { bottleneck } \\
\text { components }\end{array}$ & No & No & No & No \\
\hline $\begin{array}{l}\text { Evaluating } \\
\text { eterprise } \\
\text { architecture } \\
\text { by } \\
\text { considering } \\
\text { fuzzy } \\
\text { condition }\end{array}$ & No & No & No & Yes \\
\hline
\end{tabular}

\section{REFERENCES}

[1] Research core of information systems architecture, 2011, Shahid Beheshti university, http://isa.sbu.ac.ir

[2] Javadpour, R, 2006. Presenting an executable model to evaluate enterprise architecture by using colored Petri nets. Misc thesis, shahid Beheshti university

[3] Iacob, ME., Jonkers, H., "Quantitative Analysis of Enterprise Architectures", Proc. INTEROP-ESA Conference, Geneva, pp.23-25, 2005.
[4] C4ISR Architecture Framework version 2.0. Office of the Assistant Secretary of Defense For Command, Control, Communications and Intelligence, Washington D.C., November 1997.

[5] DoD Architecture Framework., (2003), version 1.0, DoD architecture Framework Working Group, Department of Defense.

[6] Janette Cardoso and B.pradin-chezalviel, "logic and fuzzy petri net ".

[7] Afshani, j., Harounabadi, A., Abbasi Dezfouli, M.,"A new model for designing uncertain enterprise architecture", journal of Management Science Letters, Vol 2, No 2,2012, pp. 689-696.

[8] Nematzadeh, H., Safaai Bin Deris, Maleki, H., Nematzadeh,Z. "Evaluating Reliability of System Sequence Diagram Using Fuzzy Petri Net" International Journal of Recent Trends in Engineering, Issue. 1, Vol. 1, May 2009, pp. 142-147.

Subtitles

1-OperationalEvent/Trace Description

2- Fuzzy Logic Architecture 